\title{
CARPE DiEM
}

There is a tide in the affairs of men.

Which, raken at the flood, leads on to fortune:

Omitted. all the vovage of their life

Is bound in shallows and in miseries.

- William Shakespeare

$\mathrm{T}$

HE INAUGURAL Meeting of The Oceanography Society in Monterey was an auspicious occasion for the Society. Unlike meetings of other societies to which oceanography has often been appended, our meeting provided a congenial environment for discussing the unity of oceanography as a discipline. Such discussion has long been needed. And, it comes at an opportune time.

On the day many were returning home from the meeting, a press conference was convened in Washington to release the second report of the Committee on Earth Sciences, a group representing nearly all the federal agencies involved with global environmental research. The Committee was formed in 1987, to "increase the overall effectiveness and productivity of Federal R\&D efforts directed toward an understanding of the Earth as a global system." Their report. Our Changing Planet: The FY 1990 Research Plan. calls for the implementation of a comprehensive plan to conduct the U.S. Global Change Research Program. The objectives of the Program are to monitor, understand and ultimately predict global change. The results from such a program would facilitate national and international decision making.

For the first several years of this decade, federal funding for basic research in ocean science seemed to languish in the doldrums with occasional gusts from one or another agency as they succeeded, by virtue of their individual efforts, to establish research initiatives. Now a mechanism may be developing to marshal additional resources to focus oceanography and related disciplines on a problem of far-reaching importance, both in terms of the scientific issues to be addressed and the societal impact of the research. Many oceanographers were in the vanguard of the discussions which led to the present formulation of the research program. They effectively articulated the role of the ocean in many key questions raised in the context of global change. They represented the diversity and interdependence of the various ocean disciplines in the dialogue fairly and well. In essence. they have given oceanographers a ticket to join the global science roundtable.

What should oceanographers do now? In my view, the first priority should be for us to develop a truly unified vision of our science - a vision unclouded by the partitions that have been erected for curricular or budgetary reasons-a vision that we glimpsed at the Inaugural Meeting. The second task should be to project our vision on the plan for global environmental research to insure that ocean elements are well integrated. It should be emphasized that the plan is not a fait accompli, but rather a blueprint for federal agencies to coordinate their activities and to provide a mechanism for governmental recognition and funding for these activities. But, if adopted and funded, the plan will have a major impact on oceanography as well as the other geosciences. Our input is most effective now.

A frequent subject of debate among many of those concerned with the welfare of science is the balance between individual and group efforts. Oceanographers, indefatigable individuals, often champion the former. The global environmental research problem seemingly demands the latter. Fortunately, the two need not be exclusive. Clearly the call above to participate in developing the research agenda for global scale problems will not appeal to everyone-nor should it. It is important to point out that the growth of funding for global scale problems will not pose a threat to the small, individual projects that are the mainstays of oceanography. Rather, it is hoped. any increase in funding for ocean sciences will provide enhanced capability to conduct individual research and to broaden educational opportunities for all oceanographers. 